\title{
An Empirical Study on Correlation of Learners' Motivations for Content-based Bilingual Learning with Their Achievements
}

\author{
Dahu Zheng \\ College of Foreign Languages of USST, Shanghai, 200093, China
}

\begin{abstract}
Based on seven broad dimensions of $\mathrm{L} 2$ motivation by Dornynei, and combined with the aims and characteristics of bilingual instruction in China's universities, the empirical study adopts a qualitative and quantitative approach to the study of the correlation of learners' motivation for bilingual learning with their achievements. It reveals that achievements in bilingual learning are positively correlated with seven different dimensions of motivation, with significant other-related one and self-concept-related one significantly correlated. Strategies have been suggested to help bilingual teachers to cultivate, maintain and enhance learners' motivation by means of affection in and outside classroom.
\end{abstract}

Index Terms - bilingual instruction, learner' motivation, achievement, correlation, empirical study

\section{INTRODUCTION}

Ever since bilingual instruction was carried out in China's universities in 2001, much has been discussed on a variety of issues concerning bilingual instruction in China's universities in the past 10 years, including its characteristics, instruction models, transition from college English teaching to bilingual teaching, theory applicable to bilingual instruction, learners' English level needed, implications of content-based language teaching in other countries or regions, etc. (see Zheng \&Dai 2013). These researches do provide some solutions to the problems which teachers have encountered in the process of bilingual instruction in China, but too much emphasis has been put on the teaching aspects and little on the learners. Professor Wang once pointed out that to learn well or not depends much on the learners themselves (Wang Chuming 2001). In other words, the learners' motivation plays a very important role in learning any subject. However, when the author typed in keyword "bilingual instruction" in the "China hownet" database to review the 10872 articles published in the journals from 2003 to 2013 only to find that none of the articles dealt with correlation of learners' motivations for bilingual learning with their achievement, we then may come to the conclusion that little attention has been paid to learners' motivations for bilingual learning by researchers in China.

If teachers know little about learners' motivation or attitudes towards content-based bilingual instruction, how can they help their students to learn it well? The article, combined with the aims and characteristics of bilingual instruction in China's universities, attempts to adopt a qualitative and quantitative approach to the study of the correlation of learners' motivation for bilingual learning with their achievements, using for reference the seven broad dimensions of L2 motivation by Dornynei (1998), in order to explore the effective approaches to arousing, sustaining and enhancing the learners' motivations through affective factors from the teachers in and outside classroom.

\section{LITERATURE REVIEW}

Motivation is commonly defined as internal and external factors that stimulate desire and energy in people to be continually interested in and committed to a job, role or subject, or to make an effort to attain a goal. The researches on motivation of L2 learners began in 1950s when Gardner \& Lambert $(1959,1972)$ concluded that the learners' attitude towards the target language and culture of the target language-community play a crucial role in language learning motivation after conducting a study that lasted more than 10 years. That is Socio-Educational model which had a great impact on the researches on motivations involved in L2 learning. In 1964, Vroom put forward Expectancy Value Theories by introducing psychological factors into the study, claiming that learners' motivation to acquire a second language is determined by Effort value and Expectancy, that is, motivation is determined by the value of a task. To be exact, the more likely an individual attains a goal of a task, the more incentive value he may get from the task, and the stronger motivation he/she get to finish the task. Ausubel (1968) and Maslow (1970) supplemented learning motivation with cognitive need and affective factors. Schumann $(1978,1986)$ examined the effects of personal variables such ad status, attitude etc. in the culture and suggested three strategies taken by adult learners: assimilation, rejection and acculturation. In the late 1980s, researchers challenged the social psychological approach claiming that it does not include the cognitive aspects of learning motivation, and it is not practical and does not benefit L2 learning since it is too broad to help L2 educators to generate practical guidelines. These challenges caused Self-Determination Theory to come into being. At the same time, Gardner modified his Socio-Educational model, and there came the multi era in L2 
motivation researches. In 1998, Dornynei found that almost all motivational constituents of the selected models/frameworks could be classified into seven broad dimensions after he had carried out a synthesis of thirteen different constructs by tabulating the main motivational domains underlying them.

Although the effect of motivations on L2 learners' achievement have been proved in many empirical studies at home and abroad, (Gardner,1985; Clement et al 1994; Tremblay et al 1995;Ehrman 1996; Xiaoshu 2003) no research on the effect on learners for bilingual instruction has been done. It is positively exploratory significant to do some researches on the relation between learners' motivation and their achievement. It is true that seven broad dimensions of L2 motivation by Dornyne focus on language learning, but it can be still applied to the empirical study for reference for two reasons. On one hand, one of the purposes of carrying out content-based bilingual instruction in China's universities is to improve Chinese students' English. On the other hand, in the absence of more systematical theory involved in learners' motivations for bilingual instruction it is a beneficial trial to use it for reference, in the hope of exploring a motivation theory applicable to bilingual instruction in universities in China in the future.

\section{Methodology}

\section{A. Purposes}

The paper intends to reveal how the seven broad dimensions of motivation act on learners' performance of content-based bilingual learning in universities, and what strategies can be adopted to stimulate, sustain and enhance learners' motivations.

\section{B. Instruments}

The Chinese questionnaire items administered are based on seven broad dimensions by Dornynei, and combined with the aims and characteristics of bilingual instruction in China's universities. All the items have been pretested on some of the subjects and revised on the basis of the result of pretest afterwards before questionnaire sheets were distributed to the subjects. The questionnaire consisted of 2 sections: 1) background information of the subjects, including their name, gender, scores of CET Band-4 and Band -6, the number of bilingual courses taken and their QQ number, etc.; 2) 34 items concerning seven dimensions of motivation, with 5 items from Goal-related dimension, 4 from Instrumental/pragmatic dimension, 9 from Self-concept-related dimension, 4 from Educational context-related dimension, 4 from Significant others-related dimension, 4 from Macrocontext-related dimension, 4 from Affective/integrative dimension.

The evaluation list of motivation for learners of content-based bilingual instruction is formed in accordance with Liker 7-point scale. The subjects are required to choose one from "strongly disagree" to "strongly agree" according to his/her own assessment with scores ranging from 1 point to 7 points. The higher score a subject gets in the item, the stronger motivation he/she has. For example:

When asked "The purpose of carrying out content-based bilingual instruction in China is to help students to obtain professional knowledge and to improve their English as well", the subjects are required to choose one from A, B, C, D, E, $F$ and $G$.

A. strongly agree B. fairly agree C. comparatively agree D. generally agree E. comparatively disagree F. fairly disagree $\mathrm{G}$.strongly disagree

\section{Subjects}

60 third-year students (39 male and 21 female) from School of Material Science and Engineering of USST answered the questionnaire. The Lecturer was invited to distribute the questionnaires in the classroom in order to make subjects take it seriously. 60 questionnaire sheets were distributed and collected, but 9 sheets were eliminated because some of the subjects didn't write down their names, or because some of them chose Answer A to all items. That means 51 copies are valid. 47 of the 51 sujects scored more than 425 marks in CET-Band 4, and 17 of the subjects scored more than 425 marks in CET Band-6, which means all of them are qualified to take part in bilingual instruction according to an empirical study by Han Jianxia \& Yu Liming (2007). Subsequently, 9 of the subjects took part in the follow-up complementary interview via QQ (Table 1), to complement the questionnaire findings, and to retrieve more detailed information about factors that affect the subjects in their answers to the questionnaire.

TABLE 1

INDIVIDUALS INTERVIEWED VIA QQ

\begin{tabular}{|l|l|l|l|l|l|l|l|l|l|}
\hline Name & $\mathrm{Xu}_{1}$ & Wang & Zhou & Xia & Yang & Li & Liang & Tian & $\mathrm{Xu}_{2}$ \\
\hline Sex & Male & Female & Male & Female & Male & Male & Male & Male & Female \\
\hline score & 83 & 56 & 80 & 86 & 60 & 92 & 71 & 68 & 87 \\
\hline
\end{tabular}

\section{Data Collection}

Research data consisted of the variables of the subjects' motivation in different dimensions and the variables of the subjects' score of bilingual course taken. The average value of the subjects' score came from their final exam for Materials Science and Engineering. Though the number of bilingual courses these third-year students have taken ranges 
from 3 to 7, the score of Materials Science and Engineering was selected as a variable because it is not only the most important basic course for the specialty, but also an exemplary bilingual course in Shanghai. Materials Science and Engineering (English Version, William D. Callister, John Wiely \&Sons Inc.) has been used as the teaching material for the course. Teacher Qian, an associate professor returning from USA with a doctoral degree gave the lectures. STATA 12 was then used to analyze Mean, Standard Deviation, Min and Max.

\section{RESULTS AND DisCUSSION}

\section{A. The Degree of Motivational Intensities}

Table 2 shows that the subjects' motivational intensities vary in different dimensions, but the difference is not significant. The strongest motivation comes from the Instrumental/pragmatic dimension, with its mean value highest among the seven dimensions $(\mathrm{M}=4,863, \mathrm{SD}=0.641)$, Next to Instrumental/pragmatic dimension is Goal-related one $(\mathrm{M}=4.804, \mathrm{SD}=0.851)$ and followed by Macrocontext-related dimension and Educational context-related dimension with their mean value 4.694 and 4.554 respectively. The intensity of Self-concept related motivation $(\mathrm{M}=4.183)$ is slightly stronger than that of Significant others-related dimension $(M=4.069)$. The weakest intensity of motivation is Affective/integrative dimension.

TABLE 2

STATISTICS

\begin{tabular}{|l|l|l|l|l|l|}
\hline Variable & Obs & Mean & Std.Dev. & Min & Max \\
\hline Goal-related dimension(a1-a5) & 51 & 4.804 & 0.851 & 3.200 & 6.600 \\
\hline Instrumental/pragmatic dimension(b1-b4) & 51 & 4.863 & 0.641 & 2.750 & 7 \\
\hline Self-concept-related dimension(c1-c9) & 51 & 4.183 & 0.911 & 1.778 & 5.889 \\
\hline Educational context-related dimension(d1-d4) & 51 & 4.554 & 1.091 & 1 & 6.250 \\
\hline Significant others-related dimension(e1-e4) & 51 & 4.069 & 0.885 & 2 & 5.750 \\
\hline Macrocontext-related dimension(f1-f4) & 51 & 4.694 & 0.800 & 1.600 & 6.200 \\
\hline Affective/integrative dimension(g1-g4) & 51 & 3.980 & 1.135 & 1 & 5.750 \\
\hline Score & 51 & 79.49 & 9.613 & 54 & 94 \\
\hline
\end{tabular}

TABLE 3

CORRELATIONS BETWEEN MOTIVATIONS AND ACHIEVEMENTS

CORRELATIONS BETWEEN MOTIVATIONS AND ACHIEVEMENTS
\begin{tabular}{|l|c|}
\hline Dimensions & Correlation Coefficient \\
\hline Goal-related dimension(a1-a5) & 0.092 \\
\hline Instrumental/pragmatic dimension(b1-b4) & 0.228 \\
\hline Self-concept-related dimension(c1-c9) & $0.330^{* *}$ \\
\hline Educational context-related dimension(d1-d4) & 0.230 \\
\hline Significant others-related dimension(e1-e4) & $0.412 * * *$ \\
\hline Macrocontext-related dimension(f1-f4) & 0.052 \\
\hline Affective/integrative dimension(g1-g4) & 0.0160 \\
\hline \multicolumn{2}{|c|}{ sig: $* \mathrm{P}<0.1 \quad * * \mathrm{P}<0.05 \quad * * * \mathrm{P}<0.01$} \\
\hline
\end{tabular}

Correlations between motivations and achievements (Table 3) shows that achievements in bilingual learning are positively correlated with seven different dimensions of motivation, in other words, achievements in content-based bilingual learning mainly result from student's multi-motivation though the effect on it and the intensities are different. Significant other-related

dimension is the most significantly correlated( $\mathrm{r}=0.412, \mathrm{P}<0.01)$. Next to Significant other-related

dimension is Self-concept-related dimension $(\mathrm{r}=0.330, \mathrm{P}<0.05)$, and followed by Educational context-related one and Instrumental/pragmatic one $(r=0.230$ and 0.228$)$. The rest of the dimensions are not so apparently correlated with achievement.

\section{B. Effect of Motivation in Different Dimension on Achievement}

Motivation in different dimensions has different effect on achievement, so does motivation in the same dimension on achievement. Based on the statistics and follow-up interview, how motivation in different dimensions act on the achievement of content-based bilingual learning is discussed as follows:

1) When it comes to motivation in Goal-related dimension, it does help to give the learners an impetus to content-based bilingual learning, but the effect on learners' achievement is not significant(r=0.092), which can be further proved by what the subjects said in the follow-up interview. Most of the interviewees agreed that the purpose of taking content-based bilingual course is to acquire professional knowledge and improve their English level as well, but they agreed with what Student Xia said ----“it is impractical to realize the purpose by just taking content-based bilingual courses alone." That not only means that the subjects took a reasonable view of bilingual instruction but also means that the motivation in the Goal-related dimension is not a good factor to arouse the learners' interest in content-based bilingual learning, and to improve their achievement.

2) The statistics show that the motivation in the Instrumental/pragmatic dimension plays a very important role in learners' taking bilingual courses. But it also can be seen that different motivation in this dimension has different effect on their achievement, for example, item 4 (to find a good job in the future) is positively correlated with achievement 
( $\mathrm{r}=0.409, \mathrm{P}<0.01)$ while item 3 (to earn credits) is negatively correlated with achievement $(\mathrm{r}=-0.055)$. This means that subjects value more future effect than immediate result of taking bilingual courses. Most subjects interviewed said that bilingual instruction can help them gain an advantage over others in the future, which would surely sustain and enhance their interest in bilingual learning. But in fact some subjects like Student Wang took a negative view of content-based bilingual instruction, saying that it may be putting the cart before the horse.

3) Motivation in Self-concept-related dimension is positively correlated with learners' achievement $(\mathrm{r}=0.330, \mathrm{P}<0.05)$ which can clearly seen in Item $1,2,5,6,7$ and $8\left(\mathrm{r}=0.298^{* *}, 0.305^{* *}, 0.272^{*}, 0.259^{*}, 0.386^{* * *}, 0.235^{*} . \mathrm{Sig}: * \mathrm{P}<0.1\right.$, $* * \mathrm{P}<0.05, * * * \mathrm{P}<0.001)$. Majority of the subjects believed that taking bilingual courses can not only satisfy their desire but also bring them a sense of achievement in comparison with their classmates who have not. They feel delighted in taking content-based bilingual courses, because they can not only acquire professional knowledge but also immerse themselves in English in the third years in university when there are no more English courses in curriculum. It is obvious that the desire and sense of achievement gave them an impetus to learn bilingual courses well. And most female subjects believe that taking bilingual course will enhance their literacy $(r=0.654, \mathrm{P}<0.01)$. Self-confidence and fear of failure in exam are also important factors in their motivation. It is well known that moderate degree of anxiety will help improve motivation and does good to content-based bilingual learning.

4) As to the motivation in Educational context-related dimension, the subjects generally agreed that although there are same courses in Chinese available, they've taken content-based bilingual courses not because they are required courses in the curriculum at college of Material Science and Engineering but because they want to meet the demand that the country have for them, i.e. to become bilingual persons in the future, and not because they felt dissatisfied with the effect of English learning in the first two years in university but because they want to use target language in professional knowledge. This point can be proved in their answers to Item $1(\mathrm{r}=0.280, \mathrm{P}<0.05)$ and Item $3(\mathrm{r}=0.326, \mathrm{P}<0.05)$. Those interviewed said that they can benefit a lot from taking bilingual courses, so some of them even said that they would go on taking content-based bilingual courses in the fourth year. A good case in point is that Student $\mathrm{Xu}_{2}$ even claimed that if there are no bilingual courses available in her fourth year, she would continue learning content-based bilingual material by reading original books.

5) Motivation in the Significant others-related dimension has a significant effect on learners' achievement, including teachers, parents, newspapers and magazines, and classmates. Statistics show that newspapers and their classmates have more influence on the subjects' taking bilingual courses than their teachers and parents. The means that the third years students have not followed their parents' and teachers' advice when taking courses, instead, they have formed their own thought and judgment about their own future by surfing on the net or reading newspapers, and therefore, they have their idea of what they want to learn for the future. This kind of inner thoughts and judgment would surely enhance the learner's motivation for content-based bilingual learning over long period of time. But what is worthy of note is that the teacher's English level also plays an important role in their taking content-based bilingual courses. High level of teaching staff is the prerequisite to using English as a teaching language in the content-based courses, otherwise the improvement of learners' English level cannot be guaranteed (Gu Yongqi \& Dong Lianzhong 2005). Listening to teacher's lecture two weeks prior to students' selecting courses has a great impact on their decisions on what kind of courses they are going to take, courses in Chinese or bilingual ones. Just as Student $\mathrm{Xu}_{1}$ said, bilingual teachers whose English level is not as high as Teach Qian are not qualified for the job. Still Student Tian argued that some students took bilingual courses by following suit, which can be used to explain the importance of their peers' influence.

6) Motivations in Affective/integrative dimension have the least effect on the learners' achievement $(r=0.016)$ because few of the subjects want to integrate themselves into the cultures of English-spoken countries, not to speak of becoming one citizen in the countries, therefore the learners' motivation for content-based bilingual learning can hardly be enhanced by motivation in Affective/integrative dimension. But in today's economic globalization world, the subjects who major in Material Science and Engineering, a new discipline, realize that it is inevitable for them to communicate with their counterparts in the future, so they claim that they like people from English-spoken countries and are willing to make contact with them. That means the subjects have take a reasonable view of people and culture from those countries, which may help strengthen their motivation for bilingual learning.

7) Motivations in Macrocontext-related dimension have little effect on the learners' achievement. This result tallies with the additive characteristic of content-based bilingual instruction in China's universities. Additive bilingual instruction is defined as using second or foreign language as a teaching language in the professional courses in and outside classroom, and the purpose of the instruction is not to replace the learners' mother tongue but to cultivate students to be bilingual persons, to communicate with foreign counterparts directly in the future.

\section{SugGestions}

As the findings in the study demonstrate and interviews reinforce, learners' achievements in bilingual learning are positively correlated with multi-motivation. The results of the present study also provide plenty of rich food for thought for the content-based bilingual teachers and researchers. Here are some strategies suggested to be adopted:

1) In developing learners' motivation, the teachers should find some ways to transform the objective aims required by the country into the learners' internal need, because internal need is the key to maintaining interest in bilingual learning. But the transformation should be in accordance with learners' different need. 
2) Teachers should understand the learners' desires and then try every possible means to satisfy their desire and make the learners achieve a sense of accomplishment, like communicating with foreign counterparts face-to-face online about their specialty, and at the same time try to help learners establish internal incentive mechanism in them. In addition, teachers should create some kind of moderate degree of anxiety, because too much or too little anxiety would not help enhance learners' motivation.

3) Teachers or universities should try their best to stimulate learners' motivation and need for content-based bilingual learning by providing them literature or examples or opportunities to feel the need and significance of bilingual learning.

4) Teachers should set a concrete not subtract goal for learners which is not too difficult nor too easy to reach, because "goals that are concrete but not too easy to attain will lead to better achievement." (Locke, A.1996)

5) Universities or college should tap into their teaching resources to establish a complete system of bilingual courses, making teaching contents continuous and systematic, which most universities lack in carrying out content-based bilingual instruction in China nowadays, in order to meet the learners' needs, because the contents form a connecting link between the preceding and the following.

6) Teachers or university authorities should try their best to provide opportunities for learners to put what they have learned into practice, to strengthen their motivation for content-based bilingual learning.

In short, it is necessary for the university authorities and teachers to adopt corresponding measures to cultivate, maintain and enhance the learners' motivation for content-based bilingual learning, to help achieve the aim of bilingual instruction in China better.

Of course, due to small range of subjects and short period of time, there are some limitations of the study, for example, these tentative results needs to be further testified on the extent to which they are applicable to learners from different majors or from different universities.

\section{APPENDiX. QUESTIONNAIRE SAMPLE}

Name: Gender:

Scores of CET Band-4/Band-6

Number of bilingual course taken:

Motivation Strategies for Content-based Bilingual Learning Questionnaire

Please rate the following items based on your evaluation of content-based bilingual learning. The results of the questionnaire will not affect your performance, nor will any personal information be leaked. Thank you!

1. The purpose of carrying out content-based bilingual instruction is to help students to obtain professional knowledge and improve their English as well;

2. The purpose of carrying out content-based bilingual instruction is to help students obtain bilingual ability;

3. The purpose of carrying out content-based bilingual instruction is to help students have access to frontier knowledge in their discipline, the world advanced technology and scientific thought as well directly;

4. The purpose of carrying out content-based bilingual instruction is to help students to communicate with their foreign counterparts in the future;

5. The purpose of carrying out content-based bilingual instruction is to help students to further study abroad;

6. I'v taken content-based bilingual course(s) to help me gain advantage over others in finding a job.

7. I'v taken content-based bilingual course(s) to help me adapt myself to overseas study;

8. I'v taken content-based bilingual course(s) to get credits;

9. I'v taken content-based bilingual course(s) to help me find a good job after graduation from university;

10. Content-based bilingual learning helps meet desire of me.

11. I like taking content-based bilingual courses;

12. Content-based bilingual learning helps enhance my literacy;

13. Content-based bilingual learning helps qualify myself for challenging work in the future;

14. I'v taken content-based bilingual course(s) because I like new challenges;

15. I'v taken content-based bilingual course(s) because it is required our country;

16. I feel dissatisfied at the effect of my College English learning;

17. I want to keep on learning English in my 4-year college life;

18. It is required by my school;

19. My teachers told me it is important to take content-based bilingual courses;

20. My parents ask me and encourage me to take content-based bilingual course(s);

21. I learned from newspapers that persons of bilingual ability are in great need;

22. My classmates have taken content-based bilingual courses;

23. Taking content-based bilingual course(s) helps get a pat from my teachers and classmates;

24. Content-based bilingual learning brings me a sense of achievement;

25. I have confidence in myself to learn content-based bilingual courses well;

26. My teachers' encouragement and praise contributes to my content-based bilingual learning;

27. Fear of failure drives me to hard-working;

28. I like my teachers (their character, sense of humors etc.) 
29. I value academic performance;

30. My teacher' professional knowledge and his proficiency of spoken English attract me.

31. I like people from English-spoken countries;

32. I want to become one of the people of English-spoken countries.

33. I like the cultures of English-spoken countries.

34. I like to make contact with people from English-spoken countries.

\section{REFERENCES}

[1] Ausubel, D. (1968). Educational Psychology: A Cognitive View. New York: Holt, Rinehart \& Winston.

[2] Clement, R., Z. Dornyei \& K. Noels. (1994:41). Motivation, self-confidence, and group cohesion in the foreign language classroom. Language Learning: 417-448.

[3] Cummins, J. (1991). Conversational and academic language proficiency in bilingual contexts. AILA Review 8: 75-89.

[4] Deci E. L. \& Ryan R.M. (1985). Intrinsic motivation and self-determination in human behavior. Plenum, New York.

[5] Dornyei Z. (1998:31). Motivation in second and foreign language learning. Language Teaching, 3:117-135.

[6] Ehrman, M. E. (1996). An Exploration of adult language learning motivation, self-efficacy, and anxiety. In R. L. Oxford (ed.). Language Learning Motivation: Pathways to the New Century Honolulu: The University of Hawaii Press. 103-131.

[7] Gardner R C, Lambert W E. (1972:13). Motivational variables in second language acquisition. Canadian Journal of Psychology: 266-272.

[8] Gardner R.C. (1985). .Social Psychology and Language Learning: The Role of Attitude and Motivation. London: Edward Arnold.

[9] Gu Yongqi \& Dong Lianzhong. (2005). The lessons and implications of the tentative bilingual instruction in Hong Kong. Modern Foreign Language (Quarterly), 1:44-49.

[10] Han Jianxia \& Yu Liming. (2007). English Level Students should have for content-based bilingual learning in China. Modern Foreign Languages (Quarterly), 2: 65-72.

[11] Locke E. A. (1996). Motivation through conscious goal setting. Applied \& Preventive Psychology, 5:117-124.

[12] Maslow, A. H. (1970). Motivation and Personality. New York: Harper \& Row..

[13] Schumann J. H. (1986). The acculturation model for second language acquisition. In Gingras R (ed.) Second language acquisition and foreign language teaching. Center for Applied Linguistics, Arlington, VA pp 27-107.

[14] Schumann J H. Research on the acculturation model for second language acquisition. Journal of Multilingual and Multicultural Development, 7: 379-392,

[15] Tremblay, P. \& R. Gardner. (1995:79). Expanding the motivation construct in language learning. Modern Language Journal 505-520.

[16] Vroom, V. (1964). Work and Motivation. New York: Wiley.

[17] Wang Chuming. (2001). Two major factors influencing L2 learning and their effect on L2 teaching. Foreign Language World, 6:8.-12.

[18] Xiao Su. (2003). Studies on the relationship between FL majors' multi-motivation and their achievement. Foreign Language World, 5:35-39.

[19] Zheng Dahu \& Dai Weihua. (2013). Studies on bilingual instruction in China's universities in the past decade: Review and prospects. Foreign Language World, 1:54-61.

Dahu Zheng was born in Shanghai, China in 1966. He received his Master degree in linguistics from Shanghai Teachers' University, China in 1993.

He is currently a teacher in USST Shanghai, China. His research interests include bilingual instruction, L2 acquisition. 